\title{
Sanligation technique of orchidopexy-Our experience
}

\author{
Tiwari $\mathbf{P}^{1}$, Joshi A ${ }^{2}$, Chanchlani $\mathbf{R}^{3}$ \\ ${ }^{1}$ Dr Puneet Tiwari, Assistant Professor, Department of Surgery, ${ }^{2}$ Dr Arvind Joshi, Assistant Professor, Department of \\ Surgery, ${ }^{3}$ Dr Roshan Chanchlani, Associate Professor, Department of Surgery. All are affiliated to Chirayu Medical \\ College and Hospital Bhopal, MP, India
}

Address for correspondence: Dr Roshan Chanchlani, Email: roshanchanchlani@gmail.com

\begin{abstract}
Introduction: A debate still exists in literature whether to ligate the indirect hernia sac during herniotomy in orchiopexy and hernia surgery. The study is designed with the aim to evaluate whether the ligation of hernial sac during orchiopexy is necessary to prevent the development of postoperative hernia. Material and Methods: This prospective study was conducted in 25 children with an age range of 6 months to 15 years with a diagnosis of palpable undescended testis. Of the 25 cases, 19 were unilateral and 6 were bilateral cases. Of the 19 unilateral undescended testis, 8 were right-sided and 11 were left-sided. All children underwent open orchiopexy without the ligation of the hernia sac. Results: Clinically and radiologically all the patients were followed up to a period of two years. No evidence of inguinal hernia was detected during the follow-up in any patient. Conclusion: According to this study ligation of hernial sac is not necessary during orchiopexy and leaving the remnant stump open is safe with no recurrence.
\end{abstract}

Keywords: Undescended Testes, Inguinal Hernia, Orchidopexy.

\section{Introduction}

An open herniotomy is performed along with orchidopexy for the closure of associated patent processes vaginalis in cases of palpable undescended testis. The conventional technique for undescended testis repair is high ligation of the hernial sac after proper dissection upto the deep ring, Mohta et al [1]. Observed that there is no untoward effect on the early complications and recurrence rate, if hernia sac is not ligated during herniotomy. Handa et al showed that closure of the internal ring is not necessary [2]. Similar studies in laparoscopic hernia repair in children have shown that there is no difference to simple suturing when peritoneum was incised and hernia sac resected. We have done this study on non-ligation of hernia sac during conventional orchiopexy in our institute to see the results and it's long term untoward effects.

\section{Materials and Methods}

After ethical committee approval this prospective study

was conducted between May 2011 and May 2014. 30 children with an age range of six months to 15 years

Manuscript received: $5^{\text {th }}$ Aug 2015

Reviewed: $10^{\text {th }}$ Aug 2015

Author Corrected: $19^{\text {th }}$ Aug 2015

Accepted for Publication: $27^{\text {th }}$ Aug 2015 with a diagnosis of undescended testis were included. Of the 30 cases, 20 were unilateral and 10 bilateral cases. Of the 20 unilateral undescended testis, 9 were right-sided and 11 left-sided. In all the cases, testis was palpable.In inclusion criteria those cases were taken which were not associated with clinical hernia. Baseline investigations were done, informed consent of the parents was taken and the procedure explained to the parents. All children underwent standard orchiopexy under caudal anesthesia without the ligation of the hernia sac. The hernia sac was dealt with after complete mobilization of the testis through an inguinal incision. The sac was first opened up, divided and the proximal end of the divided sac was very gently peeled off with dissecting forceps as high as possible without damaging the cord structures. This was done to bring down the testis to its normal position as it results in achievement of adequate length of the cord as describe in standard orchidopexy technique. The dissected hernia sac was not ligated and left as such. Standard orchiopexy was then performed by making subdartos pouch. All the patients were followed up regularly up to a period ranging from 18 months to 24 months. 


\section{Results}

This prospective study was conducted in 25 children with an age range of 6 months to 15 years with a diagnosis of palpable undescended testis. Of the 25 cases, $19(76 \%)$ were unilateral and 6(24\%) were bilateral cases. (Table1) Of the 19 unilateral undescended testis, 8 were right-sided and 11 were left-sidedOn basis of age 6 month -2 years 18 case were operated,amongst age 2-6 years 4 cases were operated, In age group 6-15 years 3 cases were operated.Complications after surgery in all cases was Nil,No recurrence of hernia was observed. (Table 2) All the cases were followed up for 18 months to 24 months. and not a single case was reported with evidence of hernia.

Table-1

\begin{tabular}{|l|l|}
\hline Parameters & Value \\
\hline Total no of Cases & 25 \\
\hline Unilateral cases & $19(76 \%)$ \\
\hline Bilateral cases & $6(24 \%)$ \\
\hline Right side cases & 8 \\
\hline Left sided cases & 11 \\
\hline
\end{tabular}

Table-2

\begin{tabular}{|l|l|}
\hline Age & \\
6months-2 years & 18 \\
\hline 2-6 years & 4 \\
\hline 6-15 years & 3 \\
\hline Complications minor & Nil \\
\hline Recurrence & Nil \\
\hline Discharge 24 hours & $85 \%$ \\
\hline 48 hours & $15 \%$ \\
\hline Anaesthesia given & GA with caudal epidural \\
\hline
\end{tabular}

\section{Discussion}

Undescended testis surgery is one of the commoner operations done in paediatric patients throughout the world. During laparoscopic orchidopexy performed for contralateral testicle it was found that despite non ligationof sac, the previous de peritonalized site got reperitonalized by itself and the sac which is dissected and left open deep to deep ring does not have hernia later in life. This is probably due to the closer of peritoneal defect within 24 hours by metamorphosis of the in situ mesodermal cells [3]. Shulman et al proposed that during adult herniorrhaphy, ligation of hernia sac is a needless step.[4] A study showed that with the use of a laparasocopic technique to completely resect the patent processusvaginalis and the parietal peritoneum surrounding the internal inguinal ring allowed the peritoneal scar tissue to close the area of the ring. This scarring occurs in the extent of the inguinal canal where the dissection took place, thereby causing the same peritoneal scarring and sealing of the inguinal floor.Tanyel et al.[5] showed that childhood inguinal hernia is related to smooth muscle within the wall of the sac. The smooth muscle bundles may have an important role both in prevention of obliteration and clinical outcome. The persistence of smooth muscle prevents the obliteration of processusvaginalis; myofibroblasts are found in association with smooth muscle. Undescended testis may not share the same etiologic basis as hernia, because the sacs associated with undescended testis are without smooth muscles. Recent studies concluded that herniotomy in cases of hernia alone and hernia associated with UDT, hernial sac ligation is not required [6,7]. In our study, during inguinal orchiopexy, we did not ligate the hernia sac. After freeing the hernia sac from the cord, we simply dissected the hernia sac as high as possible and cut the proximal end near deep inguinal ring. We have performed 25 cases of inguinal orchiopexy with this procedure and followed up for two years. We did not find any complication or untoward effect in any of our study cases. Advantages associated with this advancement in standard procedure are: 1 . Time saving: Several minutes of operating time are saved as we can avoid the holding of the proximal cut end of the hernial sac with multiple small haemostatic forceps and suture 
ligating it, especially when the sac is very thin and tends to tear very easily. 2. Length of testicular vessel: It is found that the most important criteria for bringing down the testes in the scrotum is the length of the testicular vessels; in this procedure extra length of the testicular vessel can be achieved by peeling off the peritoneum as high as possible. 3. Accidental ligation of the cord structures is avoided. 4. This technique decreases the anesthetic complications and reduces the undue stress of drugs and surgery [8,9,10]. A study done recently also enforced our observation that nonligation of hernia sac in paediatric age group is so far good with encouraging results [11].

\section{Conclusion}

In our study we also found that routine ligation of the hernial sac is not mandatory during orchidopexy. And it also reduces morbidity and operative time.

\section{Funding: Nil \\ Conflict of interest: None. \\ Permission of IRB: Yes}

\section{References}

1. Mohta A, Jain N, Irniraya KP, Saluja SS, Sharma S, Gupta A. Non-ligation of hernial sac during herniotomy: A prospective study. PediatrSurgInt 2003; 19: 451-2.

2. Handa R, Kale R, Harjai MM. Laparoscopic orchiopexy: Is closure of the internal ring necessary? J Postgrad Med 2005;51:266-8.

3. Kumari V, Biswas N, Mitra N, Konar H, Ghosh D, Das SK. Is ligation of hernia sac during orchiopexy mandatory?. J Indian Assoc Pediatr Surg 2009; 41: 66-7
4. Shulman AG, Amid PK, Lichtenstein IL. Ligation of hernial sac- A needless step in adult hernioplasty. IntSurg 1993; 78: 152-3.

5. Tanyel FC, Dagdeviren A, Muftuoglu S, Gursoy MH, Yuruker S, Buyukpamukcu N. Inguinal hernia revisited through comparative evaluation of peritoneum, processusvaginalis, and sacs obtained from children with hernia, hydrocele, and undescended testis. J PediatrSurg 1999; 34: 552-5.

6. Gharaibeh KI, Matani YY. To ligate or not to ligate the hernial sac in adults? Saudi Med J 2000; 21: 106870 .

7. Riquelme, M., Aranda, A., Rodriguez, C. et al, Incidence and management of the inguinal hernia during laparoscopic orchiopexy in palpable cryptorchidism: preliminary report. Pediatr. Surg.Int. 2007;23:301-304.

8. Vishal jain, Sangram Singh, Milind Joshi. Orchidopexy san ligation technique of orchidopexy. African Journal of Paediatric Surgery 2011;8:112-14.

9. Vishal Gajbhiye, Nagendra Singh, Sona Singh. Orchidopexy without ligation of hernia sac: Ourexperience. Journal of Evolution of Med and Dent Sci 2015;4:5150-53.

10. Simon C Blackburn, Stephen D Adams, Anies Mohamed Journal of Laparoendoscopic \& Advanced Surgical Techniques 2012;22(7):713-4.

11. Amanollahi, Omid Diaz, Diana Noemi Moetamedi, Vahid. New technique for herniotomy in children.Annals of Pediatric Surgery:July $2015 ; 1: 197-$ 199.

\section{How to cite this article?}

Tiwari P, Joshi A, Chanchlani R. Sanligation technique of orchidopexy-Our experience. Int J Med Res Rev 2015;3(8):858-860. doi: 10.17511/ijmrr.2015.i8.161. 